\title{
ANTECEDENTS DARI INTENTION TO PLAY DAN PENGARUHNYA TERHADAP 75 INTENTION TO PAY PADA PEMAIN MOBILE MOBA GAMES E-SPORT DI JAKARTA
}

\author{
Ivan Kristian Tojo'; Anton Wachidin Widjaja ${ }^{2}$ \\ Program Studi Magister Manajemen Universitas Pelita Harapan ${ }^{1}$ \\ Program Studi magister Manajemen Universitas Bhayangkara Jakarta Raya ${ }^{2}$ \\ Ivan.k.t.@yahoo.com'; anton.w.w.@yahoo.com²
}

\begin{abstract}
ABSTRAK
Penelitian ini bertujuan untuk mengetahui faktor-faktor yang berpengaruh kepada intention to play dan konsekuensinya pada intention to pay terhadap pemain mobile MOBA games E-Sport di Jakarta. Jumlah responden yang digunakan dalam penelitian ini adalah sebanyak 120 responden dengan status pekerjaan siswa/ mahasiswa di Jakarta yang senang bermain mobile MOBA games. Data hasil pengisian kuisioner selanjutnya dianalisis menggunakan PLS (Partial Least Square) secara deskriptif maupun kuantitatif untuk mengetahui faktor-faktor yang berpengaruh terhadap intention to play dan konsekuensinya pada intention to pay terhadap pemain mobile MOBA games E-Sport di Jakarta. Berdasarkan hasil analisis, diperoleh hasil bahwa time flexibility, challenge, diversion, fun, fantasy, dan social interaction berpengaruh positif dan signifikan terhadap intention to play. Pada hasil tersebut juga didapatkan bahwa social interaction memiliki pengaruh yang paling signifikan dibandingkan variabel independen lainnya. Namun pada arousal dan competition diperoleh hasil berpengaruh positif namun tidak signifikan terhadap intention to play, serta intention to play berpengaruh positif dan signifikan terhadap intention to pay.
\end{abstract}

Kata kunci: Mobile MOBA Games E-Sport, Time Flexibility, Arousal, Challenge, Competition, Diversion, Fun, Fantasy, Social interaction, Intention to play, Intention to pay

\section{ABSTRACT}

This study aims to determine the factors that influence intention to play and its consequences on intention to pay for MOBA games E-Sport mobile players in Jakarta. The number of respondents used in this study were 120 respondents with employment status of students in Jakarta who liked to play MOBA games. The questionnaire results were then analyzed using PLS (Partial Least Square) both descriptively and quantitatively to find out the factors that influence intention to play and the consequences on intention to pay for MOBA games E-Sport mobile players in Jakarta. Based on the results of the analysis, the results show that time flexibility, challenge, diversion, fun, fantasy, and social interaction have a positive and significant effect on intention to play. In these results it was also found that social interaction had the most significant effect compared to other independent variables. But the arousal and competition results obtained positive but not significant effect on intention to play, and intention to play have a positive and significant effect on intention to pay.

Keywords: Mobile MOBA Games E-Sport, Time Flexibility, Arousal, Challenge, Competition, Diversion, Fun, Fantasy, Social interaction, Intention to play, Intention to pay 



\section{PENDAHULUAN}

Pada era digitalisasi seperti sekarang ini perusahaan di bidang game ikut menghadapi persaingan dunia usaha yang semakin kompetitif. Meningkatnya persaingan dan jumlah pesaing menuntut setiap perusahaan untuk selalu memperhatikan kebutuhan dan keinginan konsumen agar konsumen tetap setia memainkan game yang ditawarkan tersebut. Perusahaan juga harus lebih berani untuk melakukan perubahan atau berpikir innovatif untuk dapat bersaing lebih kompetitif. Perkembangan bisnis dibidang game juga ikut berevolusi hingga membentuk genre game baru. Pertumbuhan pemakai internet dan pengguna bisnis online terus meningkat dibanding tahun-tahun sebelumnya seiring berkembangnya sistem keamanan dan kenyamanan yang semakin ditingkatkan untuk kepuasan pengguna jasa mereka.

Salah satu industri yang maju dan meningkat pesat serta menggunakan internet yaitu industri game mobile yang sekarang ini sedang naik daun. Bahkan masing-masing industri game mobile sudah sampai mengadakan eSport tournament dari lokal sampai internasional. Game telah berkembang menjadi fenomena hiburan yang serba bisa. Menurut Global Games Market Report (Newzoo, 2018) total pendapatan pada industri game di seluruh wilayah mencapai $\$ 137,9$ miliar. Namun sebagian besar dikuasai oleh wilayah Asia-Pasifik dengan pendapatan sebesar \$61,1 miliar tahun 2017.

Di tahun 2018 pendapatan pada wilayah Asia-Pasific meningkat sebesar 16,8\% menjadi $\$ 71,4$ miliar. Mengingat Indonesia termasuk pada wilayah Asia-Pasific, angka ini tentunya cukup fantastis karena dari tahun ketahun jumlah pemain untuk bermain game meningkat cukup besar.

Pada dasarnya sebagian besar gamers di Indonesia sekarang akan senang jika diberikan suatu permainan yang menantang dan ada suatu event-event hadiah jika melakukan pembayaran member premium bulanan.
Terkadang dengan adanya event tersebut membuat para gamers menjadi ingin melakukan payment. intention to pay seorang gamers dipengaruhi beberapa faktor. Faktor untuk menarik perhatian gamers tersebut sering kita temukan di berbagai genre game masing-masing, salah satunya adalah genre MOBA game. Mulai dari lamanya waktu permainan, gairah dalam permainan tersebut, tantangan didalam kerja sama tim terhadap lawan, persaingan terhadap kawan atau lawan, menjadikan permainan sebagai pembunuh waktu, menikmati pengalaman bermain, berfantasy seolah olah kita dapat menjadi character didalam game, dan juga sampai kepada interaksi sosial yang membuat game tersebut menambah teman. Hal inilah yang membuat para gamers menjadi lebih menikmati pengalaman bermain sehingga membuat mereka menjadi lebih ada minat dalam bermain.

Didalam artikel kompasiana.com pada tanggal 3 november 2018 dengan judul "Perkembangan E-Sport yang Semakin Menjanjikan di Indonesia" dengan berkembangnya teknologi, dunia E-Sport yang sekarang tidak terpaku hanya sebatas gamegame di Komputer saja, dunia E-Sport sekarang sudah merambah ke game-game di smartphone juga.

Didalam artikel kompasiana.com pada tanggal 3 november 2018 dengan judul "Perkembangan E-Sport yang Semakin Menjanjikan di Indonesia" dengan berkembangnya teknologi, dunia E-Sport yang sekarang tidak terpaku hanya sebatas gamegame di Komputer saja, dunia E-Sport sekarang sudah merambah ke game-game di smartphone juga. Hal ini menegaskan bahwa memang didalam industri game saat ini memiliki peluang yang sangat besar. Bahkan para pemainpun berkesempatan untuk menjadi gamer professional didalam duni eSport. Saat ini eSport semakin menjajikan di Indonesia. Menjadi professional gamer pun pada saat ini tidak hanya para gamer pada segmen komputer saja, namun bisa menjadi professional gamer pada segmen mobile game. Hal ini sangat mudah diakses karena 
jaman sekarang rata-rata orang sudah menggunakan smartphone untuk beraktivitas sehari-hari. Didalam artikel Tempo.co dengan judul "Survei Kepemilikan Smartphone, Indonesia Peringkat ke-24" lembaga penelitian di Amerika Serikat, Pew Research Center menerbitkan laporan tentang negara dengan orang dewasa terbanyak yang menggunakan smartphone, seperti dilansir halaman weforum, beberapa hari yang lalu. Indonesia termasuk salah satu negara yang disurvei. Dari seluruh orang dewasa pemilik HP di Indonesia, 42 persen memiliki smartphone, 28 mempunyai HP biasa, dan 29 persen tidak memiliki HP.

Melihat data Category Net Revenues 2017 - 2018, tentunya ini menjadi masalah pada genre mobile MOBA games pada market share dari tahun 2017 ke tahun 2018 yang lebih rendah atau lambat dibanding dengan genre game lainnya. Jika dilihat dari diagram tahun 2017, genre MOBA 29\% menguasai market share. Namun pada tahun 2018 angka pertumbuhan market share pada genre MOBA turun menjadi $11 \%$.

Oleh karena itu, penulis merasa tertarik untuk melakukan penelitian mengenai faktorfaktor yang mendasari atau mempengaruhi gamers di DKI Jakarta dalam melakukan pembelian item mobile MOBA games, dan faktor mana yang lebih berpengaruh dalam pengambilan keputusan ketika gamers berminat untuk bermain hingga membeli item mobile MOBA games. Penulis mengadaptasi dari model penelitian terdahulu, sebagai jurnal utama. Model penelitian diambil dari Management Journal, Souza dan Freitas (2017) dengan judul "Consumer behavior of electronic games' players: a study on the intentions to play and to pay", perbedaan penelitian terdahulu dan yang akan penulis teliti adalah lebih spesifik kepada genre game yaitu mobile MOBA games, karena saat ini penulis merasa bahwa pendapatan pada genre mobile MOBA games berada dibawah genre game lainnya. Penelitian ini hanya berfokus pada gamers yang masih berstatus siswa atau mahasiswa dan bermain pada genre mobile MOBA games serta tinggal di DKI Jakarta.
Alasannya adalah karena peneliti akan menggunakan variabel independent time flexibility yang dimana fleksibilitas waktu orang berbeda-beda, maka peneliti lebih fokus pada status pelajar atau mahasiswa yang fleksibilitas waktunya kurang lebih sama. Selain itu, peneliti menggunakan variabel dependen intention to pay, sehingga responden merupakan gamers pelajar atau mahasiswa di DKI Jakarta yang belum pernah melakukan pembelian item mobile MOBA games.

Penelitian ini akan mengkaji pengaruh time flexibility, rousal, challenge, competition, diversion, fun, fantasy, dan social interaction masing-masing mempengaruhi intention to play pada mobile MOBA games di Jakarta, serta pengaruh intention to play mempengaruhi intention to pay pada mobile MOBA games di Jakarta.

\section{TINJAUAN PUSTAKA}

\section{Intention to Pay}

Menurut Gogoi (2013), minat beli mungkin berubah atas pengaruh dari harga, kualitas, dan nilai produk atau jasa. Konsumen dipengaruhi oleh motivasi internal ataupun eksternal selama proses pembelian. Konsumen selalu berpikir jika membeli produk/jasa dengan harga murah, kemasan yang sederhana, dan image produk atau jasa yang belum dikenal memiliki risiko yang tinggi karena belum terpercaya. Media sosial digunakan oleh perusahaan sebagai sarana promosi dalam melakukan pengiklanan mengenai produknya. Tujuan utama dari iklan adalah untuk minat beli intention dalam benak konsumen mengenai produk yang dipromosikan (Keller, 2008).

Sedangkan menurut Chou dan Kimsuwan (2013) minat beli adalah suatu kondisi dimana konsumen ingin melakukan suatu transaksi terhadap produk yang dibutuhkan dan melakukan pembelian nyata serta dipengaruhi oleh berbagai macam faktor. Berbeda dengan Samuel dan Wijaya (2010) yang mengatakan 
ada tiga tahapan yang mengakibatkan minat beli seseorang yaitu:

a. Rangsangan atau stimulus, merupakan suatu hal yang mendorong terjadinya suatutindakan atau menyebabkan seseorang melakukan suatu tindakan.

b. Kesadaran, merupakan suatu bentuk pemahaman yang masuk ke dalam pikiran seseorang dan dipengaruhi oleh produk atau jasa tersebut.

c. Pencarian informasi, dapat diperoleh dari dua sumber yaitu informasi internal \& eksternal. Sumber internal merupakan informasi yang berasal dari data pribadi konsumen dalam memilih produk atau jasa yang dianggap dapat memberikan kepuasan terhadap dirinya. Sedangkan, sumber eksternal berasal dari iklan yang dilihat, atau dari sumber sosial (teman, keluarga, dan kerabat).

d.

Berdasarkan pendapat yang telah diungkapkan diatas dapat dikatakan bahwa intention to pay yaitu pengaruh motivasi baik secara internal atau eksternal dalam melakukan suatu pembelian produk yang dibutuhkan konsumen serta terjadi transaksi antara buyer dan seller.

\section{Time Flexibility}

Sedangakan menurut Hong dan $\mathrm{Xu}$ (2015), time flexibility adalah derajat dimana pemain dapat memainkan aplikasi sosial media dan dapat mengontrol waktu bermainnya. Berbeda dengan Wei dan Lu (2014), yang mengatakan bahwa time flexibility adalah seberapa jauh pengguna dapat memainkan game sosial seluler kapan saja dan dapat mengatur didalam waktu bermain.

Sedangkan Hsiao dan Chen (2016) berpendapat lain time flexibility adalah suatu konsep yang berhubungan dengan jumlah waktu yang dapat dihabiskan pengguna misalnya dengan bermain serta kemampuannya untuk menentukan dan mengatur periode waktu tersebut. Csikszentmihalyi (1977) berpendapat lain bahwa flexibilitas waktu seseorang merupakan tenggang waktu yang dihabiskan dan dapat dikendalikan oleh seseorang melalui pengalaman yang tidak dapat dilakukan pada kehidupan sehari-hari. Hal tersebut dilakukan agar seseorang dapat membuang rasa bosan, cemas, kawatir, dan gangguan kesadaran kehidupan normal seseorang (Csikzentmihalyi, 1977). Berdasarkan pendapat yang telah diungkapkan di atas dapat dikatakan bahwa time flexibility yaitu seseorang yang dapat mengendalikan atau mengkontrol waktu didalam suatu kegiatan yang sedang dilakukan.

\section{Arousal}

Menurut Sherry et al. (2006) gairah (arousal) didalam bermain video game adalah rangsangan emosi sebagai akibat dari gerakan permainan yang cepat dan grafik yang tampak nyata. Sedangkan Berbeda dengan Zillmann (1983) yang mengatakan bahwa gairah (arousal) merupakan keadaan dorongan nonspesifik yang meskipun rangsangan tertentu dapat menimbulkan gairah, dan gairah tidak secara inheren terkait dengan stimulus yang memunculkannya. Sedangkan Bridges dan Florsheim (2008) berpendapat lain bahwa gairah (arousal) adalah suatu ukuran stimulasi yang menggambarkan seberapa besar suatu peran dalam kehidupan seseorang.

Berbeda dengan Reich dan Vorderer (2015) yang mengatakan bahwa dilihat dari gairah (arousal) dalam bermain online game, gairah (arousal) merupakan reaksi fisiologis dan kognitif yang kompleks yang dialami pemain saat bermain online game. Dan akhirnya, gairah (arousal) dalam online game telah dilihat sebagai komponen kunci untuk kesenangan bermain game. Sedangkan menurut DeWall, Anderson, dan Bushman (2011) berpendapat lain bahwa gairah (arousal) adalah adalah mekanisme motivasi untuk respon agresif yang diuraikan dalam model agresi umum. Berdasarkan pendapat yang telah diungkapkan dapat dikatakan bahwa arousal adalah suatu rangsangan atau stimulasi yang membuat seseorang menjadi 
agresif untuk melakukan kegiatan yang disukai.

\section{Challenge}

Menurut Sherry et al. (2006) tantangan (challenge) merupakan dorongan diri seseorang untuk meningkatkan keterampilan atau prestasi pribadi yang lebih tinggi. Sedangkan menurut Bridges dan Florsheim (2008) tantangan (challenge) adalah perasaan bahwa kemampuan seseorang sedang dikembangkan. Berbeda dengan Nguyen (2015) yang mengatakan tantangan (challenge) adalah dorongan atau perasaan kesenangan pengguna khususnya di lingkungan hedonis.

Sedangkan Sweetser dan Wyeth (2005) berpendapat lain bahwa tantangan (challenge) adalah dorongan secara konsisten untuk berkembang didalam aspek suatu permainan. Berbeda dengan Lucas dan Sherry (2004) yang mengatakan tantangan (challenge) adalah mendorong diri sendiri untuk mengalahkan permainan atau mencapai level tertinggi berikutnya. Sedangkan Teng (2013) berpendapat lain bahwa tantangan (challenge) adalah dorongan yang dapat memotivasi gamer online untuk mengerahkan upaya yang diperlukan (meningkatkan kemampuan mereka). Dari berbagai pendapat yang telah diungkapkan di atas dapat disimpulkan bahwa challenge adalah dorongan yang dapat membuat kemampuan seseorang menjadi lebih berkembang dari pada sebelumnya.

\section{Competition}

Menurut Sherry et al. (2006) persaingan (competition) adalah suatu hal yang membuktikan kepada orang lain bahwa kepribadian seseorang tersebut memiliki keterampilan terbaik dan dapat bereaksi atau berpikir lebih cepat dari yang lain. Sedangkan menurut Giammarco, Schneider, Carswell, dan Knipe (2015) persaingan (competition) adalah salah satu alasan yang paling sering terjadi dalam permainan video game yang menggambarkan motivasi seseorang yang ingin menjadi yang terbaik dan mengalahkan teman-teman mereka.

Sedangkan Cagiltay et al., (2015) berpendapat lain bahwa persaingan (competition) adalah tujuan yang berorientasi untuk menghadiri acara tertentu di mana terdapat perdebatan secara individu atau dalam kelompok, untuk menetapkan siapa yang paling terampil dalam melaksanakan tugas tertentu. Berbeda dengan Hong et al., (2009) yang mengatakan persaingan (competition) adalah tujuan yang berorientasi pada arahan tertentu agar mencapai tujuan sendiri meskipun ini mungkin memiliki efek negatif pada pesaing lain.

Sedangkan menurut Cheng, Wu, Liao, dan Chan (2009) mengatakan bahwa persaingan (competition) adalah kegiatan pembelajaran yang terstruktur dengan baik yang memiliki potensi untuk menarik perhatian dan kegembiraan siswa. Berbeda dengan Atanasijevic-Kunc, Logar, Karba, Papic, dan Kos (2011) yang mengatakan persaingan (competition) adalah suatu permainan yang merangsang minat siswa dan meningkatkan efisiensi proses pembelajaran. Berdasarkan pendapat diatas dapat dikatakan bahwa competition adalah suatu proses yang memotivasikan seseorang untuk berusaha mengalahkan pihak lain tanpa menggunakan ancaman dan kekerasan dengan tujuan untuk mencapai sesuatu yang dapat melampaui dari yang lain.

\section{Diversion}

Menurut Sherry et al. (2006) pengalihan (diversion) adalah cara seseorang untuk menghindari stress atau tanggung jawab lainnya agar lebih mengurangi beban pikiran yang ada. Sedangkan menurut Giammarco, Schneider, Carswell, dan Knipe (2015) pengalihan (diversion) adalah sebagai cara menghindari tugas dan tanggung jawab lainnya dengan bermain video game. Berbeda dengan Lucas dan Sherry (2004) yang mengatakan pengalihan (diversion) adalah suatu cara untuk menghabiskan waktu atau mengurangi kebosanan. 
Sedangkan Liu, Liu, Yuan dan Archer (2018) berpendapat lain bahwa pengalihan (diversion) adalah situasi khusus yang dapat mempengaruhi niat dari seseorang dengan cara bermain game mobile. Berdasarkan pendapat yang telah diungkapkan di atas dapat disimpulkan bahwa diversion adalah suatu bentuk pengaruh niat seseorang untuk melakukan kegiatan lain sebagai cara menghindari tugas dan tanggung jawab atau mengurangi kebosanan.

\section{Fun}

Menurut Jin (2014) kesenangan (fun) didalam suatu permainan adalah pengalaman yang membuat para pemain merasa nyaman, tenang, lega, dan puas ketika sedang bermain. Sedangkan menurut Cohen (2014) kesenangan (fun) adalah suatu perasaan emosi yang memberikan pengalaman yang membuat seseorang nyaman ketika sedang bermain games. Berbeda dengan Shen, Wang, dam Ritterfeld (2009) yang mengatakan kesenagan (fun) adalah sensasi yang menarik perhatian pada beberapa pengalaman sosial yang telah dilakukan secara nyaman.

Sedangkan Lucas dan Sherry (2004) berpendapat lain bahwa kesenangan (fun) adalah kenyamanan yang dirasakan oleh mereka sendiri tergantung pada pengalaman seperti bermain game hiburan, narrativitas, tantangan dan kompetisi. Berdasarkan pendapat di atas dapat disebutkan bahwa fun adalah suatu pengalaman yang dirasakan seseorang secara nyaman dan menghibur ketika melakukan kegiatan yang dikerjakan.

\section{Fantasy}

Menurut Shelton (2010) fantasy adalah menggunakan alternatif lain untuk melakukan hal-hal yang tidak bisa dilakukan di dunia nyata. Berbeda dengan Sherry et al., (2006) yang mengatakan fantasy adalah suatu alternatif lain seperti bermain video game yang memungkinkan pemain melakukan halhal yang biasanya tidak dapat mereka lakukan dikehidupan nyata, seperti mengendarai mobil balap, terbang, dan sebagainya.

Sedangkan Giammarco et al., (2015) berpendapat lain bahwa fantasy adalah suatu lingkungan atau kisah yang mirip, diciptakan oleh sutradara Hollywood. Oleh karena itu, game berfungsi sebagai insentif untuk imajinasi dan kreativitas. Berdasarkan pendapat yang telah diungkapkan dapat dikatakan bahwa fantasy yaitu seseorang dapat merasakan apa yang tidak bisa dirasakan didunia nyata melalui alternatif lain.

\section{Social Interaction}

Sherry et al., (2006) mengatakan social interaction adalah alasan utama banyak orang terlibat dalam permainan video game untuk berinteraksi dengan teman dan belajar tentang kepribadian orang lain. Berbeda dengan Dalisay, Kushin, Yamamoto, Liu, dan Skalski (2015) yag mengatakan social interaction didalam permainan memiliki elemen yang melampaui permainan itu sendiri, yang melibatkan pertukaran informasi dan bertemu dengan pemain lain.

Sedangkan Verga et al., (2015) berpendapat lain bahwa social interaction adalah pengaruh dua arah antara mitra, yang cenderung mengubah perilaku mereka secara timbal balik. Berdasarkan pendapat yang telah diungkapkan di atas dapat disebutkan bahwa social interaction adalah kegiatan pertukaran informasi atau pengaruh dua arah antara seseorang dengan orang lain.

\section{Intention to Play}

Menurut Wei dan Lu (2014) intention to play adalah kebutuhan seseorang yang dipenuhi melalui hiburan (permainan) yang bertujuan untuk memberikan rasa puas dan nyaman kepada para pemain. Sedangkan menurut Wu dan Liu (2007) intention to play adalah fungsi kepercayaan pada situs web online game, sikap terhadap bermain online game, kesenangan bermain online game, dan norma subyektif. Berbeda dengan Plass, 
O'Keefe, Homer, dan Hayward (2013) yang mengatakan bahwa intention to play adalah permainan kolaboratif yang meningkatkan niat pemain untuk memainkan game lagi dan merekomendasikan game tersebut kepada yang lain.

Sedangkan Koo (2009) berpendapat lain bahwa intention to play pada online game didefinisikan sebagai pemain yang sangat mudah terpengaruh untuk memainkan game online. Berdasarkan teori yang telah diungkapkan tersebut, dapat dikatakan bahwa intention to play yaitu pengaruh niat terhadap seseorang dalam memainkan permainan yang disukai.

\section{Model Penelitian}

Terdapat sepuluh variabel yang akan digunakan pada penelitian ini untuk menjelaskan tentang hubungan antar variabel yang digunakan pada model penelitian sehingga membentuk hipotesis penelitian, yaitu time flexibility, arousal, challenge, competition, diversion, fun, fantasy, social interaction, intention to play, dan intention to pay. Dependent variable dalam penelitian ini yaitu intention to pay. Berikut kerangka teori pada penelitian ini:

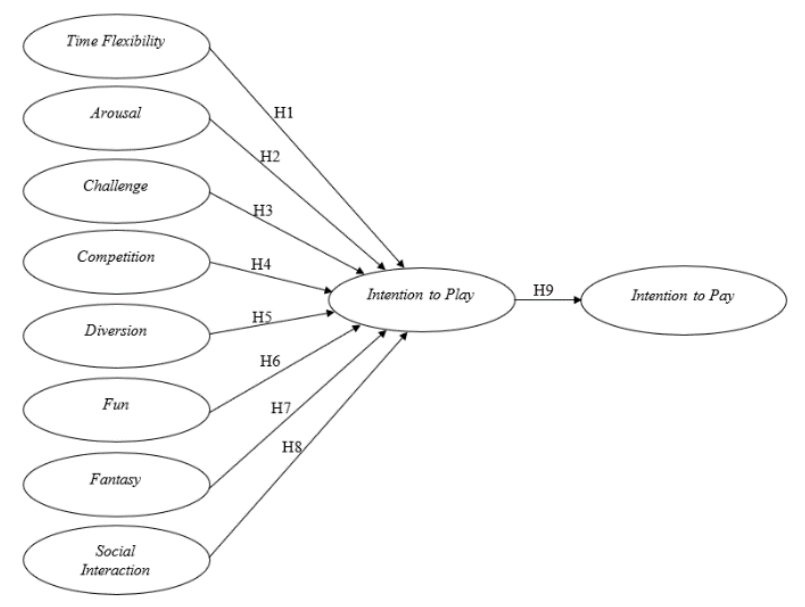

Gambar 1. Model Penelitian Sumber: Olahan Peneliti

\section{Hipotesis}

Berdasarkan perumusan masalah, teori yang telah diuraikan dan hasil penelitian sebelumnya, maka akan diajukan hipotesis sebagai berikut:

Menurut Wei dan Lu (2014), kebanyakan konsumen bermain game di waktu senggang mereka masing-masing, karena bermain game diwaktu tersebut merupakan solusi untuk menghabiskan waktu bagi mereka. Sedangkan Hsiao dan Chen (2016) berpendapat lain bahwa konsep time flexibility memiliki hubungan dengan jumlah waktu yang dihabiskan pengguna untuk bermain, serta dapat menentukan dan mengendalikan waktu bermain mereka. fleksibilitas waktu dianggap sebagai konstruk yang memengaruhi niat untuk bermain di antara konsumen game, karena pengguna dapat bermain kapan saja atau peluang untuk bermain tinggi (Pe-Than, Goh, \& Lee, 2014). Berbeda dengan Hong dan $\mathrm{Xu}$ (2015) yang mengatakan time flexibility mempengaruhi pengguna untuk dapat memainkan aplikasi sosial media dan dapat mengontrol waktu bermainnya didalam minat untuk bermain. Dari penjelasan di atas dapat dihipotesakan: Time Flexibility Mempengaruhi Secara Positif Terhadap Intention To Play.

Menurut Reich dan Vorderer (2015) gairah (arousal) dalam bermain online game telah dilihat sebagai komponen kunci untuk kesenangan bermain game. Sedangkan Sherry, Lucas, Greenberg dan Lachlan (2006) berpendapat bahwa gairah (arousal) didalam bermain video game dapat merangsang emosi sebagai akibat dari gerakan permainan yang cepat dan grafik yang tampak nyata.

Berbeda dengan Souza dan Freitas (2017) yang mengatakan pemain umumnya lebih peka dan penuh perhatian saat bermain, pikiran mereka hanya terfokus pada permainan itu, yang kadang-kadang membuat mereka tidak menyadari rangsangan lain. Keadaan ini dapat meningkatkan adrenalin, tekanan darah dan detak jantung, dan semua efek ini terkait dengan perasaan pemain saat itu. Games dapat mengarahkan pemain untuk menarik perhatian, aktivitas, kewaspadaan mendorong mereka untuk bermain lebih dan 
lebih, yang membuat arousal menjadi elemen penting dari niat untuk bermain. Gairah (Arousal) diakui sebagai variabel untuk niat bermain. Arousal Mempengaruhi Secara Positif Terhadap Intention To Play.

Suatu tantangan pada minat bermain seseorang mampu meningkatkan tingkat pembelajaran para pemain: semakin banyak upaya untuk menyelesaikan tantangan, semakin besar pembelajaran (Souza \& Freitas, 2017). Sedangkan Sherry et al., (2006) berpendapat lain bahwa game elektronik yang dapat menantang kemampuan pemain akan meningkatkan niat mereka untuk bermain. Berbeda dengan Sweetser dan Wyeth (2005) yang mengatakan tantangan (challenge) dapat mendorong secara konsisten untuk berkembang didalam aspek niat bermain seseorang. Challenge Mempengaruhi Secara Positif Terhadap Intention To Play.

Menurut Atanasijevic-Kunc, Logar, Karba, Papic, dan Kos (2011) persaingan (competition) didalam suatu permainan dapat merangsang minat siswa dan meningkatkan efisiensi proses pembelajaran. Persaingan (competition) merupakan salah satu alasan yang paling sering terjadi dalam permainan video game yang menggambarkan motivasi seseorang yang ingin menjadi yang terbaik dan mengalahkan teman-teman mereka (Giammarco, Schneider, Carswell, \& Knipe, 2015).

Sedangkan Souza dan Freitas (2017) berpendapat lain bahwa selain tantangan yang ditimbulkan oleh permainan, beberapa pemain mencoba untuk melakukan misi dengan tingkat kesulitan yang lebih tinggi daripada yang lain, atau untuk mengalahkan mereka dalam kompetisi yang diusulkan oleh permainan. Untuk memenangkan pertandingan ini, banyak pemain menghabiskan berjam-jam belajar, sehingga mereka akhirnya bisa menjadi yang terbaik dan memenangkan semua kompetisi. Competition Mempengaruhi Secara Positif Terhadap Intention To Play.
Menurut Sherry et al., (2006) video game sering digunakan untuk melampiaskan stress, mengisi waktu, bersantai, atau karena tidak ada hal lain yang dapat dilakukan. Sedangkan Giammarco, Schneider, Carswell, dan Knipe (2015) berpendapat diversion menggambarkan keinginan untuk bermain game karena hal tersebut dapat lebih menenangkan pikiran, mengurangi stress, mengurangi kebosanan, dan bahkan menghindari tanggung jawab lain.

Berbeda dengan Liu, Liu, Yuan dan Archer (2018) yang mengatakan diversion dapat mempengaruhi niat dari seseorang dengan cara bermain game mobile. Diversion harus dianggap sebagai semacam situasi pengguna dalam bermain game mobile. Secara umum, kita dapat memanfaatkan konsentrasi waktu untuk melakukan hal-hal penting. Tetapi masih ada beberapa waktu untuk istirahat atau waktu luang. Misalnya, waktu menunggu bus dan waktu perjalanan dalam perjalanan singkat. Dalam situasi yang membosankan seperti itu, orang dapat memilih untuk bermain game mobile untuk membuat pengalihan. Diversion Mempengaruhi Secara Positif Terhadap Intention To Play.

Cohen (2014) berpendapat bahwa seseorang yang nyaman ketika sedang bermain games akan berpengaruh kepada perasaan emosi yang memberikan pengalaman seseorang menjadi lebih menyenangkan. Sedangkan Lucas dan Sherry (2004) mempunyai pendapat lain bahwa kenyamanan yang dirasakan mereka sendiri berpengaruh pada pengalaman dalam bermain game hiburan, narrativitas, tantangan dan kompetisi. Para pemain atau pengguna mencari hiburan dan kesenangan melalui game yang disukai (Jin, 2014). Fun mempengaruhi secara positif terhadap Intention to Play.

Menurut Sherry et al., (2006) video game dapat membuat seseorang dapat melakukan hal-hal yang biasanya tidak dapat 
mereka lakukan didunia nyata seperti misalnya terbang, pergi ke luar angkasa dan sebagainya. Berbeda dengan Giammarco et al., (2015) yang mengatakan game berpengaruh sebagai insentif untuk imajinasi dan kreativitas seseorang. Melalui fantasi, game menjadi cara untuk alternatif lain yang tidak bisa dilakukan didunia nyata (Kahn et al., 2015). Fantasy Mempengaruhi Secara Positif Terhadap Intention To Play

Sherry et al., (2006) berpendapat bahwa social interaction merupakan alasan utama banyak orang ketika bermain video game. Saat ini banyak yang menggunakan video game untuk saling berinteraksi dengan teman serta belajar tentang kepribadian orang lain. Sedangkan McGloin, Hull, dan Christensen (2016) berpendapat lain bahwa konstruk social interaction berpengaruh pada permainan didalam bersaing, berkompetisi atau dapat saling membantu satu sama lain. Berbeda dengan Dalisay, Kushin, Yamamoto, Liu, dan Skalski (2015) yang mengatakan interaksi sosial dalam permainan memiliki faktor yang dapat melampaui permainan itu sendiri, dan hal itu akan melibatkan pertukaran informasi serta bertemu dengan pemain lain. Dari penjelasan di atas dapat dirumuskan hipotesis: Social Interaction Mempengaruhi Secara Positif Terhadap Intention To Play.

Wang dan Li (2012) mengatakan bahwa kenyamanan yang dirasakan merupakan faktor yang mempengaruhi secara positif didalam niat konsumen untuk membeli. Sedangkan Park dan Lee (2011) berpendapat bahwa gamer yang puas dengan game yang dimainkan tidak harus memiliki niat pembelian item game online. Namun ketika pengguna memutuskan untuk membayar, pengguna mendapatkan hak istimewa item yang dibelinya. Hal itulah niat bermain dapat mempengaruhi niat membayar pengguna. Berbeda dengan Souza dan Freitas (2017) yang mengatakan bahwa niat untuk bermain memiliki tingkat pengaruh yang tinggi terhadap niat untuk membayar, namun harus diperkuat dengan strategi freemium dan game play-to-pay adalah cara yang efisien untuk merangsang niat bermain dan, akhirnya, niat untuk membayar. Dengan demikian dapat dirumuskan hipotesis: Intention to Play mempengaruhi secara positif terhadap Intention to Pay.

\section{METODE PENELITIAN}

Penelitian yang dilaksanakan ini menggunakan metode penelitian kuantitatif dimana jenis penelitian ini adalah pengujian hipotesis. Metode penelitian ini adalah metode penelitian yang digunakan untuk meneliti sampel atau populasi tertentu yang dimana teknik pengambilan sampel dilakukan secara random dan pengumpulan data dilakukan dengan menggunakan instrument penelitian (Sugiyono, 2013).

Sumber dan Cara Pengambilan Data. Untuk mendapatkan data penelitian ini menggunakan dua macam data, yaitu: data primer dan data sekunder. Pada penelitian ini pengumpulan data primer menggunakan survei yang dilakukan dengan cara menyebarkan kuisioner berupa link secara online. Survei merupakan salah satu teknik pengumpulan data dengan memberikan pertanyaan-pertanyaan seputar variabel yang akan diteliti. Pertanyaan yang digunakan dalam penelitian ini adalah pertanyaan tertutup dengan memberikan skala Likert untuk jawabannya. Penyebaran kuisioner yang berupa link dilakukan pada bulan Maret - Mei 2019 secara acak melalui aplikasi Whatsapp kepada warga Negara Indonesia. Link tersebut terhubung dengan kuisioner online yang akan diisi oleh responden. Aplikasi kuisioner online yang digunakan adalah Google form.

Data sekunder adalah data yang tidak diperoleh secara langsung dari nara sumber seperti penelitian yang sudah ada, laporan, artikel, buku, publikasi, dan sebagainya. Pada penelitian ini, peneliti melakukan studi kepustakaan dari buku dan jurnal-jurnal terkait sikap konsumen, norma subjektif, dan intensi pembelian beserta faktor-faktor yang mempengaruhinya baik secara umum maupun secara khusus terhadap suplemen makanan. Informasi ini digunakan sebagai landasan teori 
serta dalam mengembangkan hipotesis. Informasi lainnya mengenai data pasar terkini, definisi, kebijakan pemerintah dan lain-lain untuk menunjang penelitian ini diperoleh dari regulasi dan keputusan yang dikeluarkan pemerintah, artikel, serta internet.

\section{Teknik Sampling}

Pengambilan sampel dengan teknik NonProbability Sampling dapat dilakukan dengan beberapa metode diantaranya dengan metode: Convenience Sampling. Metode Convenience Sampling umumnya digunakan pada situasi yang tidak memungkinkan menggunakan metode penarikan sampel dengan cara lain. Misalnya ketika data sangat sulit diperoleh dengan menggunakan cara-cara random atau nonrandom oleh karena keterbatasan data. Menurut Sekaran dan Bougie (2016) Convenience Sampling merupakan teknik pengambilan sampel yang mengambil elemenelemen termudah saja. Pemilihan elemen ini, sepenuhnya bergantung pada penilaian peneliti atau pewawancara sehingga peneliti bebas menentukan elemen yang paling mudah.

\section{Sampling Prosedur}

Responden dari penelitian ini adalah masyarakat Jakarta yang bermain mobile MOBA games serta melakukan pembelanjaan (payment) didalam game tersebut, dengan usia kurang dari 17 tahun sampai lebih dari 34 tahun. Penulis mendistribusikan link kuesioner melalui whatsapp, line, instragram dan email dengan menanyakan terlebih dahulu apakah calon responden menyukai permainan mobile MOBA games atau tidak. Jika responden menyukai permainan mobile MOBA games maka responden melanjutkan mengisi kuesioner.

\section{Metode Analisis Data}

Uji hipotetis akan menggunakan Structural Equation Model (SEM), yang merupakan sekumpulan teknik yang memungkinkan pengujian beberapa variabel dependen dengan beberapa variabel independen secara simultan. SEM mampu menguji struktur hubungan antar variabel menggunakan serangkaian persamaan yang mirip dengan rangkaian persamaan multiple regression (Hair et al, 2014). SEM dapat dibagi menjadi dua, yaitu covariance based dan component based. Covariance based SEM sangat dipengaruhi oleh jumlah sampel, karena sampel yang terlalu kecil akan berpotensi menghasilkan error. Component Based SEM dapat dilakukan pada pendekatan dengan Partial Least Square (PLS). PLS berorientasi pada analisis component based predictive model, sedangkan covariancebased SEM lebih berorientasi pada building model yang dimaksudkan untuk lebih menjelaskan covariance dari semua indikator yang diteliti (Ghozali \& Latan, 2015). Metode yang akan digunakan dalam penelitian ini ialah metode Partial Least Square (PLS) Structural Equation Model (SEM), atau disebut PLS SEM dikarenakan penelitian ini merupakan penelitian yang bersifat prediktif. Pada dasarnya metode ini serupa dengan multiple regression analysis, hanya saja lebih efektif karena lebih fleksibel dalam jumlah sampel dan memudahkan ketika model yang digunakan rumit (Hair et al., 2014). PLS-SEM bertujuan untuk menguji hubungan prediktif antar konstruk dengan melihat apakah ada ketergantungan atau pengaruh antar konstruk tersebut, parameter ketepatan model prediksi dilihat dari nilai koefisien determinasi (Rsquare).

Metode PLS memiliki keunggulan tersendiri diantaranya: data tidak harus berdistribusi normal multivariate (indikator dengan skala katergori, ordinal, interval, hingga rasio dapat digunakan pada model yang sama), dan ukuran sampel tidak harus besar. Selain digunakan untuk konfirmasi teori, PLS juga dapat digunakan untuk menjelaskan ada atau tidaknya hubungan antara variabel laten (Ghozali, 2011). Alat uji yang akan digunakan dalam penelitian ini aialah SmartPLS. Untuk pengujian hipotesis dengan PLS dilakukan dengan metode boothstrapping yang menggunakan seluruh sampel asli. Jumlah sampel yang direkomendasikan untuk 
bootstrapping pada penelitian ini adalah sebesar 200 sampai 5000 untuk mengoreksi standard error estimate PLS (Ghozali \& Latan, 2015). Outer model penelitian ini akan dievaluasi dengan melihat signifikansi, $R$ Square, dan multikolinearitas.

Signifikansi digunakan pada pengujian hipotesis yang dilakukan dengan melihat nilai probabilitas dan t-statistik. Nilai signifikansi yang digunakan adalah $t$-value sebesar 1,645 untuk signifikansi level $5 \%$ sehingga kriteria penerimaan hipotesis adalah nilai t-statistic harus lebih besar dari nilai $t$-value (Ghozali \& Latan, 2015). Nilai t-value tersebut didapatkan dari tabel statistik critical value for the $T$ distribution. Perubahan yang terjadi pada nilai $R$-square menggambarkan pengaruh variabel independen tertentu terhadap variabel dependennya. Nilai $R$-square 0.67 memberikan kesimpulan bahwa pengaruh variabel independen terhadap variabel dependennya itu kuat. Untuk nilai $R$-square o.33 memberikan kesimpulan bahwa pengaruh variabel independen terhadap variabel dependennya itu moderat dan 0.19 memberikan kesimpulan bahwa pengaruh variabel independen terhadap variabel dependennya itu lemah (Ghozali \& Latan, 2015).

\section{HASIL PENELITIAN DAN PEMBAHASAN}

Pada Penelitian ini, kuisioner penelitian disebarkan baik secara online dan tatap muka kepada mobile MOBA games players untuk mendapatkan jawaban dari responden yang diinginkan. Jumlah sampel yang diterima dan memenuhi kriteria yang telah ditentukan dapat diolah adalah 120 responden. Responden yang memenuhi kriteria adalah responden yang berstatus siswa atau mahasiswa, aktif memainkan mobile $M O B A$ games, dan tinggal di wilayah DKI Jakarta.

Tidak ditemukan sampel yang tidak lengkap atau tidak memenuhi syarat dalam penelitian ini, karena pertanyaan penyaringan pada sampel yang memenuhi syarat dilakukan terlebih dahulu sebelum indikator-indikator ditampilkan kepada responden dan indikator untuk kuisioner ini telah diatur agar responden mengisi lengkap semua pertanyaan. Jika ada pertanyaan yang tidak diisi, maka responden yang bersangkutan tidak akan dapat mengirimkan hasil pengisian kuisioner di Google Form.

\section{Profil Demografi Responden}

Dari 120 responden yang memenuhi syarat untuk berpartisipasi dalam penelitian ini, responden dikelompokkan dan dijelaskan berdasarkan karakteristik demografi yaitu jenis kelamin, usia, status pendidikan dan pengeluaran bulanan responden seperti yang dijelaskan pada tabel dibawah ini.

\begin{tabular}{|c|c|c|c|}
\hline Karakteristik & Uraian & Jumlah & Persentase \\
\hline \multirow{2}{*}{$\begin{array}{l}\text { Jenis } \\
\text { Kelamin }\end{array}$} & Laki - laki & 90 & $75 \%$ \\
\hline & Perempuan & 30 & $25 \%$ \\
\hline \multirow[t]{3}{*}{ Usia } & $\begin{array}{l}\text { Dibawah umur } \\
17 \text { tahun }\end{array}$ & 26 & $22 \%$ \\
\hline & $17-25$ tahun & 86 & $72 \%$ \\
\hline & $\begin{array}{l}\text { Diatas umur } 26 \\
\text { tahun }\end{array}$ & 8 & $6 \%$ \\
\hline \multirow[t]{2}{*}{ Status } & Siswa & 25 & $21 \%$ \\
\hline & Mahasiswa & 95 & $79 \%$ \\
\hline \multirow[t]{5}{*}{$\begin{array}{l}\text { Pengeluaran } \\
\text { per Bulan }\end{array}$} & $\begin{array}{ll}< & \mathrm{Rp} \\
3.000 .000 & \end{array}$ & 59 & $49 \%$ \\
\hline & $\begin{array}{lr}\text { Rp } & 3.000 .001 \\
- & R p \\
5.000 .000 & R\end{array}$ & 37 & $31 \%$ \\
\hline & $\begin{array}{l}\operatorname{Rp} 5.000 .001- \\
\operatorname{Rp} 7.000 .000\end{array}$ & 10 & $8 \%$ \\
\hline & $\begin{array}{l}\mathrm{Rp} 7.000 .001- \\
\mathrm{Rp} 10.000 .000\end{array}$ & 9 & $8 \%$ \\
\hline & $>_{10.000 .000} \mathrm{Rp}$ & 5 & $4 \%$ \\
\hline
\end{tabular}

\section{Tabel 1. Profil Demografi Responden}

Sumber: Pengolahan Data Primer (2019)

Dari uraian demografi yang dijabarkan pada tabel 4.1, terlihat bahwa dari total 120 responden, jenis kelamin yang paling banyak menjadi responden adalah laki-laki sebanyak $75 \%$ atau 90 responden, kisaran usia responden terbanyak adalah 18-25 tahun yaitu sebanyak $72 \%$ atau 86 responden dari total responden keseluruhan. Status yang terbanyak diantara responden adalah mahasiswa sebanyak $79 \%$ atau 95 responden. Pengeluaran rata-rata responden terbanyak dari total keseluruhan responden adalah dibawah 3 juta rupiah sebanyak $49 \%$ atau 59 responden. 


\section{Hasil Uji Hipotesis}

Penelitian ini menguji hipotesis menggunakan one tailed dengan level signifikansi sebesar 5\%. Walaupun data responden pada penelitian ini hanya 120 responden, tetapi nilai $t$-value yang ditetapkan sebagai tolak ukur dari pengaruh antar variabel haris diatas 1.64 dikarenakan oleh responden dianggap tidak terhingga pada saat dilakukan boothstrapping dengan data yang ada. Hasil uji dilakukan bootstrapping karena model ini adalah model reflektif. Hasil uji hipotesis ini dapat dilihat pada tabel dibawah ini.

\begin{tabular}{|l|c|c|l|}
\hline Hipotesis & $\begin{array}{c}\text { Standardized } \\
\text { Coefficient }\end{array}$ & $\begin{array}{c}\text { t- } \\
\text { statistik }\end{array}$ & Keterangan \\
\hline $\begin{array}{l}\text { H1: Time } \\
\text { Flexibility } \\
\rightarrow \text { Intention } \\
\text { to Play }\end{array}$ & 0.101 & 1.978 & Didukung \\
\hline $\begin{array}{l}\text { H2: Arousal } \\
\rightarrow \text { Intention } \\
\text { to Play }\end{array}$ & 0.058 & 0.553 & $\begin{array}{l}\text { Tidak } \\
\text { Didukung }\end{array}$ \\
\hline $\begin{array}{l}\text { H3: } \\
\text { Challenge } \\
\rightarrow \text { Intention } \\
\text { to Play }\end{array}$ & 0.141 & 1.82 & Didukung \\
\hline $\begin{array}{l}\text { H4: } \\
\text { Competitio } \\
n\end{array}$ & & & \\
$\begin{array}{l}\text { Intention to } \\
\text { Play }\end{array}$ & 0.061 & 0.774 & Tidak \\
\hline $\begin{array}{l}\text { H5: } \\
\text { Diversion } \\
\rightarrow \text { Intention } \\
\text { to Play }\end{array}$ & & & Didukung \\
\hline $\begin{array}{l}\text { H6: Fun } \rightarrow \\
\text { Intention to } \\
\text { Play }\end{array}$ & 0.312 & 3.319 & Didukung \\
\hline $\begin{array}{l}\text { H7: Fantasy } \\
\rightarrow \text { Intention } \\
\text { to Play }\end{array}$ & & 2.003 & Didukung \\
\hline $\begin{array}{l}\text { H8: Social } \\
\text { Interaction } \\
\rightarrow \text { Intention } \\
\text { to Play }\end{array}$ & 0.148 & 1.932 & Didukung \\
\hline $\begin{array}{l}\text { H9: } \\
\text { Intention to } \\
\text { Play } \\
\text { Intention to } \\
\text { Pay }\end{array}$ & & & \\
\hline
\end{tabular}

Tabel 2. Hasil Uji Hipotesis

Sumber: Hasil Pengolahan Data Penelitian (2019)
Pada tabel diatas, dapat dilihat hasil uji hipotesis dari hipotesis-hipotesis yang telah dijabarkan. Dilihat dari nilai standardized coefficient dari setiap hipotesis, dapat ditarik kesimpulan bahwa semua hipotesis berpengaruh positif, dengan tingkat besar pengaruh yang berbeda-beda. Dilihat dari nilai t-statistik setiap hipotesis, kesembilan hipotesis menunjukkan hasil bahwa enam variabel dependen pengaruh yang signifikan terhadap intention to play dan satu variabel mediasi pengaruh signifikan terhadap intention to pay dari seseorang. Keenam hipotesis variabel dependen tergolong berpengaruh moderat untuk menjelaskan intention to play ( $r$-square $=0.625$ ) dan hipotesis variabel mediasi tergolong berpengaruh moderat untuk menjelaskan intention to pay $(R$-square $=0.385)$.

Penelitian ini menggunakan keyakinan 95\% dimana $t$-statistik > 1.64 yang berarti bahwa apabila nilai $t$-statistik > 1.64 maka hipotesis memiliki pengaruh yang signifikan, sedangkan apabila nilai $t$-statistik $<1.64$, maka hipotesis memiliki pengaruh yang tidak signifikan.

Hipotesis 1 yang menyatakan bahwa time flexibility memiliki pengaruh positif terhadap intention to play diterima karena nilai $t$ statistik lebih besar dari 1.64 yaitu sebesar 1.978 dan nilai standardized coefficient-nya sebesar 0.101. Hal ini berarti bahwa variabel time flexibility memiliki pengaruh positif yang signifikan terhadap intentention to play.

Hipotesis 2 yang menyatakan bahwa arousal memiliki pengaruh positif terhadap intention to play ditolak karena nilai $t$-statistik lebih kecil dari 1.64 yaitu sebesar 0.553 dan nilai standardized coefficient-nya sebesar 0.057. Hal ini berarti bahwa variabel arousal memiliki pengaruh positif yang tidak signifikan terhadap intentention to play.

Hipotesis 3 yang menyatakan bahwa challenge memiliki pengaruh positif terhadap intention to play diterima karena nilai $t$ statistik lebih besar dari 1.64 yaitu sebesar 1.82 
dan nilai standardized coefficient-nya sebesar 0.141. Hal ini berarti bahwa variabel challenge memiliki pengaruh positif yang signifikan terhadap intentention to play.

Hipotesis 4 yang menyatakan bahwa competition memiliki pengaruh positif terhadap intention to play ditolak karena nilai t-statistik lebih kecil dari 1.64 yaitu sebesar 0.774 dan nilai standardized coefficient-nya sebesar 0.061. Hal ini berarti bahwa variabel competition memiliki pengaruh positif yang tidak signifikan terhadap intentention to play.

Hipotesis 5 yang menyatakan bahwa diversion memiliki pengaruh positif terhadap intention to play diterima karena nilai $t$ statistik lebih besar dari 1.64 yaitu sebesar 2.003 dan nilai standardized coefficient-nya sebesar 0.137. Hal ini berarti bahwa variabel diversion memiliki pengaruh positif yang signifikan terhadap intentention to play.

Hipotesis 6 yang menyatakan bahwa fun memiliki pengaruh positif terhadap intention to play diterima karena nilai $t$-statistik lebih besar dari 1.64 yaitu sebesar 3.319 dan nilai standardized coefficient-nya sebesar 0.312 . Hal ini berarti bahwa variabel fun memiliki pengaruh positif yang signifikan terhadap intentention to play.

Hipotesis 7 yang menyatakan bahwa fantasy memiliki pengaruh positif terhadap intention to play diterima karena nilai $t$ statistik lebih besar dari 1.64 yaitu sebesar 1.932 dan nilai standardized coefficient-nya sebesar 0.148. Hal ini berarti bahwa variabel fantasy memiliki pengaruh positif yang signifikan terhadap intentention to play.

Hipotesis 8 yang menyatakan bahwa social interaction memiliki pengaruh positif terhadap intention to play diterima karena nilai $t$-statistik lebih besar dari 1.64 yaitu sebesar 3.341 dan nilai standardized coefficient-nya sebesar 0.32. Hal ini berarti bahwa variabel social interaction memiliki pengaruh positif yang signifikan terhadap intentention to play.
Hipotesis 9 yang menyatakan bahwa intention to play memiliki pengaruh positif terhadap intention to pay diterima karena nilai t-statistik lebih besar dari 1.64 yaitu sebesar 12.874 dan nilai standardized coefficient-nya sebesar 0.621. Hal ini berarti bahwa variabel intention to play memiliki pengaruh positif yang signifikan terhadap intentention to pay.

\section{Pembahasan Model Penelitian}

Berdasarkan uji hipotesis pada model penelitian dengan menggunakan SmartPLS 3.o, dapat dijelaskan bahwa secara nyata hasil penelitian dari sembilan hipotesis yang diajukan terdapat tujuh hipotesis sejalan dengan penelitian sebelumnya dan dua hipotesis tidak sejalan dengan penelitian sebelumnya. Dari data pada pengujian hipotesis sebelumnya, dapat dinyatakan bahwa hasil model penelitian pada pengujian hipotesis kedua dalam penelitian ini dapat dinyatakan bahwa arousal memiliki pengaruh yang positif namun tidak signifikan terhadap intention to play. Hasil uji hipotesis ini tidak sejalan dengan penelitian menurut Reich \& Vorderer (2015) yang menyatakan adanya pengaruh positif yang signifikan dari variabel arousal terhadap variabel intention to play. Sherry, Lucas, Greenberg dan Lachlan (2006) juga tidak mengkonfirmasi bahwa gairah (arousal) didalam bermain video game dapat merangsang emosi sebagai akibat dari gerakan permainan yang cepat dan grafik yang tampak nyata.

Namun penelitian yang dilakukan di Jakarta ini mengkonfirmasi penemuan yang dilakukan oleh Souza \& Freitas (2017) pada penelitian sebelumnya yang menyatakan bahwa pemain tidak termotivasi untuk bermain, atau terus-menerus bermain oleh kegembiraan atau emosi yang berasal dari permainan. Gairah terkait dengan sensasi fisiologis yang dapat memberikan pemain merasa nyaman sehubung dengan stimulus yang diterima saat bermain, hal itu sulit dikenali (Souza \& Freitas, 2017). Dari pernyataan diatas dapat dinyatakan bahwa arousal berpengaruh positif pada intention to play namun belum tentu memiliki cukup 
pengaruh kuat yang signifikan. Hal ini tergantung pada populasi dan target penelitian ini dilakukan.

Penelitian ini pada kuisioner behavior sekitar 20\% dari responden bermain lebih dari 30 match dalam seminggu, dan sebagian besar dari responden sebesar 40\% bermain 10-30 match dan sebesar 40\% responden bermain kurang dari 10 match. Dilihat dari pernyataan responden yang kurang dominan bermain mobile MOBA games lebih dari 30 match dalam seminggu akan lebih sedikit untuk menyetujui bahwa permainan yang terkait dengan keadaan obsesif yang dapat membuat permain tidak dapat mematikan permainan selama beberapa jam. Hal ini dapat dilihat bahwa memang gairah (arousal) dalam bermain mobile MOBA games cenderung kurang. Didalam penelitian ini, variabel gairah (arousal) pada orang Jakarta mempunyai dampak positif namun memiliki pengaruh cukup lemah yang tidak signifikan terhadap pertimbangan seseorang didalam minat bermain, sehingga hal ini tidak mendukung penelitian sebelumnya mengenai pengaruh arousal terhadap intention to play.

Hasil model penelitian pada pengujian hipotesis ke empat competition memiliki pengaruh yang positif namun tidak signifikan terhadap intention to play. Hal ini dapat dinyatakan bahwa hipotesis keempat tidak didukung. Hasil uji hipotesis ini tidak sejalan dengan penelitian Menurut Atanasijevic-Kunc et al., (2011) yang menyatakan adanya pengaruh positif yang signifikan dari variabel competition terhadap variabel intention to play. Giammarco et al., (2015) juga tidak mengkonfirmasi bahwa persaingan (competition) memiliki pengaruh positif yang signifikan dari variabel competition terhadap variabel intention to play. Namun penelitian yang dilakukan di Jakarta ini mengkonfirmasi penemuan yang dilakukan oleh Souza \& Freitas (2017) pada penelitian sebelumnya yang menyatakan bahwa persaingan memiliki efek negatif untuk niat bermain karena ketika seorang pemain kalah, hal tersebut membuat tidak merasa cenderung untuk ingin bermain lagi atau terus bermain. Dari pernyataan diatas dapat dinyatakan bahwa competition berpengaruh positif pada intention to play namun belum tentu memiliki cukup pengaruh kuat yang signifikan. Hal ini tergantung pada populasi dan target penelitian ini dilakukan. Pada kuisioner behavior penelitian ini, sekitar 40\% dari responden tertarik bermain mobile MOBA games karena sekedar senang-senang atau ikut-ikutan, dan sebagian besar dari responden sebesar $71,7 \%$ tertarik bermain mobile MOBA games karena banyak teman yang bermain. Dilihat dari pertanyaan behavior, responden rata-rata tertarik bermain mobile MOBA games hanya karena sekedar ikut-ikutan dan banyak teman yang bermain mobile MOBA games lebih dominan dibanding bermain secara serius. Hal ini dapat dilihat bahwa memang persaingan (competition) dalam bermain mobile MOBA games cenderung kurang karena responden rata-rata bermain mobile MOBA games hanya karena sekedar senang-senang atau ikutikutan dan banyak teman yang bermain mobile MOBA games. Didalam penelitian ini, variabel persaingan (competition) pada orang Jakarta mempunyai dampak positif namun memiliki pengaruh cukup lemah yang tidak signifikan terhadap pertimbangan seseorang didalam minat bermain karena kurangnya minat responden dalam persaingan yang dikarenakan bermain mobile MOBA games lebih dominan untuk bermain sekedar senangsenang dan banyak teman bermain dibanding bermain secara serius.

Hasil model penelitian pada pengujian hipotesis kedelapan mempresentasikan social interaction berpengaruh positif dan signifikan terhadap intention to play. Hasil uji hipotesis ini adalah hipotesis variabel independent yang paling berpengaruh didalam hasil model penelitian ini. Hasil uji hipotesis ini sejalan dengan penelitian menurut Sherry et al., (2006) yang menyatakan adanya pengaruh positif yang signifikan dari variabel social interaction terhadap variabel intention to play. Penelitian yang dilakukan di Indonesia ini juga mengkonfirmasi penemuan yang dilakukan oleh McGloin et al., (2016). Hal yang 
sama juga ditemukan pada penelitian Dalisay et al., (2015) yang menyatakan bahwa adanya pengaruh positif yang signifikan dari variabel social interaction terhadap variabel intention to play. Namun penelitian yang dilakukan di Jakarta ini juga mengkonfirmasi penemuan yang dilakukan oleh Souza \& Freitas (2017) bahwa variabel social interaction berpengaruh positif yang signifikan terhadap variabel intention to play. Didalam penelitian ini, variabel social interaction pada orang Indonesia mempunyai dampak positif dan memiliki pengaruh cukup kuat yang signifikan terhadap pertimbangan seseorang didalam minat bermain. Hal yang dapat dilakukan adalah membuat permainan yang dapat menyatukan kebersamaan seseorang dengan orang lain, atau pembuatan event yang dapat membuat permainan mobile MOBA games dapat lebih mudah berinteraksi dengan sesama pemain.

Hasil model penelitian pada pengujian hipotesis kesembilan mempresentasikan intention to play memiliki pengaruh positif dan signifikan terhadap intention to pay. Hasil uji hipotesis ini sejalan dengan penelitian menurut Wang \& Li (2012) yang menyatakan adanya pengaruh positif yang signifikan dari variabel intention to play terhadap variabel intention to pay. Penelitian yang dilakukan di Jakarta ini juga mengkonfirmasi penemuan yang dilakukan oleh Park \& Lee (2011). Namun penelitian yang dilakukan di Indonesia ini juga mengkonfirmasi penemuan yang dilakukan oleh Souza \& Freitas (2017) bahwa variabel intention to play berpengaruh positif yang signifikan terhadap variabel intention to pay.

Didalam penelitian ini, variabel intention to play pada orang Jakarta mempunyai dampak positif dan memiliki pengaruh cukup kuat yang signifikan terhadap pertimbangan seseorang didalam minat beli seseorang. Hal yang dapat dilakukan adalah membuat permainan yang dapat membuat seseorang merasa nyaman dalam bermain dan membuat event-event yang membuat para player menjadi lebih berminat dalam bermain mobile MOBA games sehingga pemain atau player menjadi lebih ada dorongan untuk melakukan pembayaran terhadap game tersebut. Ketika suatu permainan mobile MOBA games dapat dimainkan secara nyaman dan ada rasa suatu tantangan tersendiri yang unik, maka hal ini semakin mempengaruhi minat bermain dan semakin berpengaruh kepada minat membeli seseorang dalam pembelian item didalam mobile MOBA games tersebut.

\section{Kesimpulan}

Terdapat beberapa kesimpulan yang dapat diambil berdasarkan hasil pembahasan penelitian yang sudah dilakukan di bab sebelumnya. Kesimpulan-kesimpulan yang dapat diambil adalah sebagai berikut:

1. Time flexibility berpengaruh positif terhadap intention to play. Semakin tinggi time flexibility dari seseorang, semakin tinggi intention to play seseorang.

2. Arousal mempunyai pengaruh yang positif namun tidak signifikan terhadap intention to play.

3. Challenge berpengaruh positif terhadap intention to play. Semakin tinggi challenge dari seseorang, semakin tinggi intention to play seseorang.

4. Competition mempunyai pengaruh yang positif namun tidak signifikan terhadap intention to play.

5. Diversion berpengaruh positif terhadap intention to play. Semakin tinggi diversion dari seseorang, semakin tinggi intention to play seseorang.

6. Fun berpengaruh positif terhadap intention to play. Semakin tinggi fun dari seseorang, semakin tinggi intention to play seseorang.

7. Fantasy berpengaruh positif terhadap intention to play. Semakin tinggi fantasy dari seseorang, semakin tinggi intention to play seseorang.

8. Social interaction berpengaruh positif terhadap intention to play. Semakin tinggi social interaction dari seseorang, semakin tinggi intention to play seseorang.

9. Intention to play berpengaruh positif terhadap intention to pay. Semakin tinggi intention to play dari seseorang, semakin tinggi intention to pay seseorang. 
Jadi dapat disimpulkan bahwa variabel arousal dan competition pada model penelitian ini mempunyai pengaruh positif namun tidak signifikan terhadap variabel intention to play. Sedangkan variabel time flexibility, challenge, diversion, fun, fantasy, dan social interaction memiliki pengaruh yang positif dan signifikan terhadap intention to play, serta variabel intention to play memiliki pengaruh yang positif dan signifikan terhadap intention to pay.

\section{Keterbatasan dan Saran Penelitian Berikutnya}

Terdapat beberapa keterbatasan yang dihadapi dalam penelitian ini. Keterbatasanketerbatasan tersebut salah satunya adalah membuat variabel arousal (gairah) dan competition tidak signifikan. Hal ini dikarenakan sebagian besar dari responden sebesar $40 \%$ bermain 10- 30 match dan sebesar $40 \%$ responden bermain kurang dari 10 match. Dilihat dari pernyataan responden yang kurang dominan bermain mobile MOBA games lebih dari 30 match dalam seminggu akan lebih sedikit untuk menyetujui bahwa permainan yang terkait dengan keadaan obsesif yang dapat membuat permain tidak dapat mematikan permainan selama beberapa jam. Hal ini dapat dilihat bahwa memang gairah (arousal) dalam bermain mobile MOBA games cenderung kurang. Kemudian sekitar $40 \%$ dari responden tertarik bermain mobile MOBA games karena sekedar senang-senang atau ikut-ikutan, dan sebagian besar dari responden sebesar $71,7 \%$ tertarik bermain mobile MOBA games karena banyak teman yang bermain. Dilihat dari pertanyaan behavior, responden rata-rata tertarik bermain mobile MOBA games hanya karena sekedar ikut-ikutan dan banyak teman yang bermain mobile MOBA games lebih dominan dibanding bermain secara serius. Hal ini dapat dilihat bahwa memang competition dalam bermain mobile MOBA games cenderung kurang.

Untuk penelitian selanjutnya disarankan untuk lebih mencari responden yang lebih cenderung untuk intens dalam bermain game seperti responden pro player atau responden yang serius menekuni untuk bermain game sehingga mendapatkan kualitas responden yang lebih bergairah serta lebih kompetitif didalam bermain mobile MOBA games. Syarat yang digunakan untuk pembatasan penelitian ini adalah status pekerjaan responden haruslah siswa atau mahasiswa, tinggal di wilayah Jakarta, dan suka bermain mobile MOBA games. Tidak semua orang Jakarta yang menyukai permainan genre mobile MOBA games. Hal ini membuat beberapa kali data yang harus dibuang dan memakan waktu yang cukup lama untuk mengumpulkan responden. Penyebaran kuisioner melalui $e$ mail, dan media sosial juga sedikit tidak efektif dibandingkan dengan penyebaran kuisioner secara tatap muka, karena pesan elektronik mempunyai kemungkinan untuk diabaikan dan terlupakan. Oleh karena itu, saran untuk penelitian berikutnya adalah mengambil area penelitian yang dapat dijangkau dan didatangi dengan mudah untuk mendapatkan responden yang tepat dan akurat sesuai dengan pembatasan yang ditetapkan.

Penelitian ini membahas sepuluh variabel, yaitu time flexibility, arousal, challenge, competition, diversion, fun, fantasy, social interaction, intention to play, dan intention to pay di mana belum diketahui apakah setelah para gamers merasa puas dengan melakukan pembelian item in game atau pembayaran event in game, mereka akan kembali membeli item in game atau melakukan pembayaran event in game tersebut atau tidak. Pada penelitian selanjutnya juga dapat meneliti beberapa variabel tambahan seperti repurchase intention, atau menambahkan variabel dependen atau mediasi lain seperti eWOM source yang berpengaruh terhadap intention to play untuk mengetahui apakah dari rekomendasi orang lain dapat menjadi alasan yang mengukur intention to play, intention to pay, dan re-purchase intention dari gamers.

\section{DAFTAR PUSTAKA}

Alfarizi, M. K. (2019, 3 4). Survei Kepemilikan Smartphone, Indonesia Peringkat ke24. Retrieved from Tempo.co: 
https://tekno.tempo.co/read/1181645

/survei-kepemilikan-smartphone-

indonesia-peringkat-ke-

24/full\&view $=$ ok

Ames, C. (1984). Achievement attributions and self-instructions under competitive and individualistic goal structures. Journal of Educational Psychology, 478-487.

Atanasijevic-Kunc, M., Logar, V., Karba, R., Papic, M., \& Kos, A. (2011). Remote Multivariable Control Design Using a Competition Game. IEEE TRANSACTIONS ON EDUCATION, 54(1), 97-103.

Bridges, E., \& Florsheim, R. (2008). Hedonic and utilitarian shopping goals: The online experience. Journal of Business Research, 309-314.

Brown, J. D. (2011). Likert Items and Scales of Measurement? Shiken: JALT Testing \& Evaluation SIG Newsletter, 15(1). 1014.

Cagiltay, N. E., Ozcelik, E., \& Ozcelik, N. S. (2015). The effect of competition on learning in games. Computers \& Education, 35-41.

Chen, H., Wigand, R., \& Nilan, M. (1999). Optimal experience of Web activities. Computer in Human Behavior, 15(5), 585-608.

Cheng, H. N., Wu, W. M., Liao, C. C., \& Chan, T.-W. (2009). Equal opportunity tactic: Redesigning and applying competition games in classrooms. Computers \& Education, 866-876.

Chou, C.-M., \& Kimsuwan, A. (2013). Factors Affecting Purchase Intention of Online Game Prepayment Card-Evidence from Thailand. Journal of Internet Banking and Commerce.

Cohen, E. L. (2014). What makes good games go viral? The role of technology use, efficacy, emotion and enjoyment in players' decision to share a prosocial digital game. Computers in Human Behavior, 321-329.

Csikszentmihalyi, M. (1977). Beyond Boredom and Anxiety, second printing. San Francisco: Jossey-Bass.

Csikszentmihalyi, M. (2004). Materialism and the evolution of consciousness, In: T.
Kasser \& A. D. Kanner (Eds.). In , Psychology and consumer culture: The struggle for a good life in a materialistic world (91-106). Washington, DC: American Psychological Association.

Dalisay, F., Kushin, M. J., Yamamoto, M., Liu, Y.-I., \& Skalski, P. (2015). Motivations for game play and the social capital and civic potential of video games. New Media \& Society, 17 (9), 1399-1417.

DeWall, C. N., Anderson, C. A., \& Bushman, B. J. (2011). The General Aggression Model: Theoretical Extensions to Violence. Psychology of Violence, 1(3), 245-258.

Engl, S., \& Nacke, L. E. (2013). Contextual Influences on mobile player experience - A game user experience model. Entertainment Computing, 4(1), 8391.

Ghozali, I., \& Latan, H. (2015). Partial Least Squares : Konsep, Teknik dan Aplikasi Menggunakan Program SmartPLS 3.0 (4th ed). Semarang: Badan Penerbit Universitas Diponegoro.

Giammarco, E. A., Schneider, T. J., Carswell, J. J., \& Knipe, W. S. (2015). Video game preferences and their relation to career interests. Personality and Individual Differences, 98-104.

Gogoi, B. J. (2013). STUDY OF ANTECEDENTS OF PURCHASE INTENTION AND ITS EFFECT ON BRAND LOYALTY OF PRIVATE LABEL BRAND OF APPAREL. International Journal of Sales \& Marketing, 3(2), 73-86.

Grizzard, M., Tamborini, R., Sherry, J. L., Weber, R., Prabhu, S., Hahn, L., \& Idzik, P. (2015). The Thrill Is Gone, but You Might Not Know: Habituation and Generalization of Biophysiological and Self-reported Arousal Responses to Video Games. Communication Monograph, 82(1), 64-87.

Hair, J. F., Black, W. C., Babin, B. J., \& Anderson, R. E. (2014). Multivariate data analysis. Upper Saddle River: NJ: Prentice Hall. 
91 | Antecedents Dari Intention To Play Dan Pengaruhnya Terhadap Intention To Pay Pada Pemain

Hoffman, D. L., \& Novak, T. P. (1996). Marketing and hypermedia computermediated environments: conceptual foundations. Journal of Marketing, $60(3), 50-68$.

Hong, H., \& Xu, D. (2015). An Empirical Study on Continuance Using Intention of Mobile Social Apps. Association for Information Systems.

Hong, J.-C., Hwang, M.-Y., Lu, C.-H., Cheng, C.-L., Lee, Y.-C., \& Lin, C.-L. (2009). Playfulness-based design in educational games: a perspective on an evolutionary contest game. Interactive Learning Environments, 17(1), 15-35.

Hsiao, K. L., \& Chen, C. C. (2016). What drives in-app purchase intention for mobile games? An examination of perceived values and loyalty. Electronic Commerce Research and Applications, 18-29.

Jin, C.-H. (2014). The role of users' motivations in generating social capital building and subjective well-being: The case of social network games. Computers in Human Behavior, 29-38.

Kahn, A. S., Shen, C., Lu, L., Ratan, R. A., Coary, S., Hou, J., . . . Williams, D. (2015). The Trojan Player Typology: A cross-genre, cross-cultural, behaviorally validated scale of video game play motivations. Computers in Human Behavior, 354-361.

Katkoff, M., Heikkinen, K., Kumar, A., \& Macmillan, A. (2019, 2 19). 2019 Predictions \#9: Say Hello to the New Breed of Battle Royale Games. Retrieved from Deconstructor of Fun: https://www.deconstructoroffun.com/ blog/2019/2/19/4s8e1vlxju2ltvfosjj53 5bkf7eby9

Kevino, S. (2018, 5 17). Apa itu MOBA? Retrieved from Esportsnesia: https://esportsnesia.com/penting/apa -itu-moba/

Koo, D.-M. (2009). The moderating role of locus of control on the links between experiential motives and intention to play online games. Computers in Human Behavior, 25, 466-474.
Kotler, dan Keller. (2012). Manajemen Pemasaran (12 ed.). Jakarta: Erlangga.

Kotler, P., \& Armstrong, G. (2014). Principle of Marketing, 15th edition. New Jersey: Pearson Prentice Hall.

Kotler, P., \& Keller, K. L. (2012). Marketing Management 13. New Jersey: Pearson Prentice Hall.

Kotler, Philip and Gary Armstrong. (2008). Prinsip-prinsip Pemasaran (12 ed.). Jakarta: Erlangga.

Laksamana, J. A., \& Purwanegara, M. S. (2016). FACTORS INFLUENCING USERS' INTENTION TO PLAY IN INNOVATIVE MOBILE GAMING USAGE CASE STUDY OF VALVE IN INDONESIA. JOURNAL OF BUSINESS AND MANAGEMENT, 5(6), 764-772.

Levine, D. M., Stephan, D. F., \& Szabat, K. A. (2017). Statistics for Managers Using Microsoft ${ }^{\circledR}$ Excel (8 th ed). England: Pearson Education Limited.

Liu, Y., Liu, D., Yuan, Y., \& Archer, N. (2018). Examining situational continuous mobile game play behavior from the perspectives of diversion and flow experience. Information Technology \& People.

Lucas, K., \& Sherry, J. L. (2004). Sex Differences in Video Game Play:: A Communication-Based Explanation. Communication Research.

Lutz, R. J., \& Guiry, M. (1994). Intense Consumption Experiences: Peaks, Performances, and Flows, Winter Marketing Educators' Conference, February. St. Petersburg, FL.

Malhotra, N. K. (2010). Marketing Research: An Applied Orientation, 6th Edition. New Jersey: Pearson Education, Inc.

Marcellino, S. (2018, 11 3). Perkembangan eSport yang Semakin Menjanjikan di Indonesia. Retrieved from Kompasiana: https://www.kompasiana.com/sandy marcellino/5bdd4399bde5757e4a1f5a 89/perkembangan-esport-yangsemakin-menjanjikan-di-indonesia 
McGloin, R., Hull, K. S., \& Christensen, J. L. (2016). The social implications of casual online gaming: Examining the effects of competitive setting and performance outcome on player perceptions. Computers in Human Behavior, 173-181.

Nguyen, D. (2015). Understanding Perceived Enjoyment and Continuance.

Pe-Than, E. P., Goh, D. H.-L., \& Lee, C. S. (2014). Making work fun: Investigating antecedents of perceived enjoyment in human computation games for information sharing. Computers in Human Behavior, 88-99.

Plass, J. L., O'Keefe, P. A., Homer, B. D., \& Hayward, E. O. (2013). The Impact of Individual, Competitive, and Collaborative Mathematics Game Play on Learning, Performance, and Motivation. Educational Psychology, 105(4), 1050-1066.

Reich, S., \& Vorderer, P. (2015). Online Games, Player Experiences in. In R. Mansell, \& P. H. Ang, The International Encyclopedia of Digital Communication and Society. Germany: John Wiley \& Sons, Inc.

Sekaran, U., \& Bougie, R. (2016). Reasearch Methods For Business: A Skill Building Approach. New York: John Willey \& Son.

Shelton, A. K. (2010). Defining the lines between virtual and real world purchases: Second Life sells, but who's buying? Computers in Human Behavior, 1223-1227.

Shen, C., Wang, H., \& Ritterfeld, U. (2009). Serious games and seriously fun games: Can they be one and the same? 48-62.

Sherry, J. L., Lucas, K., Greenberg, B. S., \& Lachlan, K. (2006). Video Games Uses and Gratifications as Predictors of Use and Game Preference. 24, 213-224.

Souza, L. F., \& Freitas, A. F. (2017). Consumer behavior of electronic games' player: a study on the intentions to play and to pay. (52), 419-430.

Sugiyono. (2013). Metode penelitian pendidikan: (pendekatan kuantitatif, kualitatif dan $R \quad \& \quad D)$. Bandung: Alfabeta.

Sweetser, P., \& Wyeth, P. (2005). GameFlow: A Model for Evaluating Player Enjoyment in Games. ACM Computers in Entertainment, 3(3).

Teng, C.-I. (2013). How Do Challenges Increase Customer Loyalty to Online Games? CYBERPSYCHOLOGY, BEHAVIOR, AND SOCIAL NETWORKING, 16(12), 884-891.

Verga, L., Bigand, E., \& Kotz, S. A. (2015). Play along: affects of music and social interaction on word learning. frontiers in Psychology.

Wang, W.-T., \& Li, H.-M. (2012). Factors influencing mobile services adoption: a brand-equity perspective. Internet Research, $\quad 22(2), \quad 142=179$. doi:10.1108/10662241211214548

Wei, P. S., \& Lu, H. P. (2014). Why do people play mobile social games? An examination of network externalities and of uses and gratifications. Emerald Group Publishing Limited, 24(3), 313331.

Wu, J., \& Liu, D. (2007). The Effects of Trust and Enjoyment on Intention to Play Online Games. Journal of Electronic Commerce Research, 8(2), 128-140.

Yanda, F. F. (2018, 9 22). Makin Diakui Sejak Asia Games, Seperti Apa Perkembangan eSport di Indonesia? Retrieved from Tribuntechno: http://www.tribunnews.com/techno/2 018/09/22/makin-diakui-sejak-asiagames-seperti-apa-perkembanganesport-di-indonesia

Zillman, D. (1983). Transfer of excotation in emotional behavior. In J. T. Cacioppo \& R. E. Petty (Eds.). In Social psychophysiology: A sourcebook (215-240). New York: NY: Guilford Press. 
93 | Antecedents Dari Intention To Play Dan Pengaruhnya Terhadap Intention To Pay Pada Pemain Mobile Moba Games E-Sport di Jakarta 